\title{
OS CAMINHOS DO LIXO NA CIDADE DO RIO DE JANEIRO
}

\author{
HUMBERTO ALVES DE QUEIROZ ${ }^{1}$ \\ GLAUCIO JOSÉ MARAFON ${ }^{2}$
}

\section{Resumo}

A destinação dos resíduos sólidos nas cidades tem sido uma questão permanente para os gestores, pois a adoção de técnicas de coleta e destinação e o surgimento de empresas com o propósito de garantir a limpeza e o aperfeiçoamento técnico para confinamento do lixo têm sido um desafio permanente. Destarte, objetiva-se neste ensaio analisar os caminhos da geração e destinação dos resíduos sólidos urbanos do município do Rio de Janeiro, evidenciando-se assim a rede de coleta e destinação desses resíduos sólidos na cidade em questão.

Palavras-chave: resíduos sólidos, cidade do Rio de Janeiro, rede de coleta e destinação do lixo.

\section{Abstract}

The disposal of solid waste in cities has been an ongoing issue for managers, for the adoption of collection and disposal techniques, the emergence of companies in order to ensure cleanliness and technical training for garbage confinement, has been a challenge permanent. Thus, the objective is to test that analyze the ways of generation of municipal solid waste in the municipality of Rio de Janeiro and its destination, is shown thus the network of collection and disposal of solid waste in the city of Rio de Janeiro.

Keywords: solid waste, city of Rio de Janeiro, collection network and disposal of waste.

\section{INTRODUÇÃO}

Os resíduos sólidos urbanos, quando acumulados, propiciam a infestação de vetores que causam ameaças à saúde da população. Nos sistemas de drenagem, podem provocar entupimentos e, por consequência, enchentes. Nos rios, sua concentração promove a poluição das águas e o desequilíbrio da vida marinha. Em terrenos a céu aberto, contaminam o solo e o lençol freático, além de emitirem gases tóxicos na atmosfera.

É necessário que as cidades sejam preservadas dos males causados pela geração crescente de resíduos sólidos urbanos. A coleta diária, no Brasil, foi de 201.058 toneladasldia no ano de 2012. No município do Rio de Janeiro, no ano de 2011, foram coletadas 9.666 toneladas $\left\langle\right.$ dia $^{3}$. O cenário demanda a constituição de mecanismos legais que ordenem a gestão desses resíduos e a construção de uma infraestrutura capaz de captar e confinar, em local adequado, o quantitativo crescente de matérias passíveis de descarte.

Embora o Brasil tenha 3,6\% da população mundial e responda por 3,5\% do Produto Interno Bruto mundial, descarta $5,5 \%$ do total de resíduos planetários, com uma taxa de reaproveitamento baixa apenas $13 \%$ do total de resíduos são reciclados (WALDMAN, 2010).

O município do Rio de Janeiro possui uma área de $1.255 \mathrm{~km}^{2}$ e uma população de 6.300 .000 habitantes, resultando na geração de 1,6 kg ไhab.ldia. A destinação de lixo para aterros ou lixões é indispensável, mas, ainda que necessária, a escolha do local desperta rejeição, pois:

\footnotetext{
1 Mestre em Geografia (PPGEO/UERJ).humbertohistoria@hotmail.com

2 Professor Associado (PPGEO/UERJ).glauciomarafon@hotmail.com

3 Dados da comlurb.
} 
Estão também se criando "novos territórios indesejáveis", ou segregados, como as áreas de depósito de lixo doméstico, de lixo radioativo e de usinas nucleares. Estes territórios indesejáveis [são] resultado de intercâmbio entre determinadas regiões de um mesmo país, ou melhor, de uma mesma cidade, como é o caso dos depósitos de lixo doméstico, que devem ser lançados cada vez mais longe e que têm servido para "a sobrevivência" dos mais pobres que coletam os restos. (RODRIGUES, 1998, p. 79).

A modificação do arranjo constituído para a gestão dos resíduos sólidos urbanos estabelece uma rede, uma nova infraestrutura para a gestão desses resíduos que, incorporada à cidade, reconfigura o espaço.

A geração dos resíduos sólidos urbanos é resultado das intensas relações comerciais que se expandem em porções do espaço, induzidas pelos processos de produção e consumo. Demanda, portanto, novas construções, implicando configurações e reconfigurações espaciais. Desse modo, Rio afirma que:

A infraestrutura de transporte e de comunicação condiciona os fluxos de pessoas, mercadorias, informações e direciona as trocas comerciais em todas as escalas. A cada atividade correspondem, portanto, uma temporalidade e uma espacialidade que se manifestam concretamente no espaço. (RIO, 2012, p. 156).

A oportunidade de progresso técnico declarada por agentes envolvidos no processo de reordenamento do fluxo de resíduos oferece as condições para a intensificação das trocas entre atores sociais distintos e distantes. Há fluidez nas relações comerciais, de intercâmbio técnico e permuta de informações, a partir de objetos técnicos específicos, implantados a partir da rede que, segundo Santos, é:

Formada por troços, instalados em diversos momentos, diferentementes datados, muitos dos quais já não estão presentes no período atual e cuja substituição no território também se deu em momentos diversos. Mas essa sucessão não é aleatória. Cada movimento se opera na data adequada, isto é, quando o movimento social exige uma mudança morfológica e técnica. (sANTos, 1996, p. 177).

Como a produção industrial cresce continuamente, demandando distribuição, fluidez e movimento indispensáveis ao produzido, e não sendo a produção organizadora da circulação, mas, ao contrário, sendo a circulação quem define a produção, entendemos a partir de Santos que:

Criam-se objetos e lugares distintos a favorecer a fluidez: oleodutos, gasodutos, canais, autopistas, aeroportos, teleportos. Constroem-se edifícios temáticos, bairros inteligentes, tecnopolos. Esses objetos transmitem valor às atividades que deles se utilizam, nesse caso, podemos dizer que eles “circulam”. É como, também, fossem fluxos. (sAnTos, 1996, p. 185).

O objetivo geral deste trabalho será analisar a nova configuração espacial de Resíduos Sólidos Urbanos (RSU) do município do Rio de Janeiro. Para tanto, leva em consideração as diretrizes determinadas pela legislação em âmbito federal, estadual e municipal, em especial a Política Nacional de Resíduos Sólidos Urbanos, e utiliza instrumentos técnicos e conceituais da Geografia que permitem a demonstração da espacialização do lixo, descrevendo os fixos e fluxos ligados à nova rede geográfica que emerge a partir de uma demanda da população, o destino final do lixo.

A investigação contou com dados oficiais disponibilizados por instituições representativas do poder público, da sociedade organizada, do meio acadêmico, de estabelecimentos jurídicos e de associações empresarias, bem como com dados resultantes de entrevistas com técnicos de empresas públicas e privadas envolvidas na construção do novo fluxo de resíduos sólidos urbanos do município do Rio de Janeiro.

Para os dados relativos aos resíduos sólidos urbanos no Brasil, recorremos a publicações diversas, com destaque para informações da ABRELPE (Associação Brasileira de Empresas de Limpeza) e do CEMPRE (Compromisso Empresarial para Reciclagem).

O levantamento de dados referentes ao descarte e à geração de resíduos no mundo foi realizado por meio de buscas em relatórios e pesquisas publicados pelo Banco Mundial, onU (Organização das 
Nações Unidas) e Iswa (International Solid Waste Association).

Entre as informações oriundas do poder público, destacamos os documentos disponibilizados pelo IPp (Instituto Pereira Passos), IPEA (Instituto de Pesquisa Econômica Aplicada) e IBGE (Instituto Brasileiro de Geografia e Estatística).

\section{ORGANIZAÇÃO ESPACIAL DA COLETA PÚBLICA DO LIXO NO MUNICÍPIO DO RIO DE JANEIRO: DO PASSADO AO PRESENTE}

No Brasil, dados coletados pela Pesquisa Nacional por Amostra de Domicílio e pela Pesquisa Nacional de Saneamento Básico, realizadas pelo IBGE, apontam que no ano 2000 foram geradas no país aproximadamente 157 mil toneladas de lixo domiciliar e comercial por dia. Em $2013^{4}$, o total de resíduos coletados foi de 76.387.200 toneladas, ou 209.280 toneladas por dia. No município do Rio de Janeiro, em 2012, foram destinadas aos aterros sanitários 4.053.461 toneladas de lixo5 ${ }^{5}$.

O lixo é indissociável das atividades desenvolvidas pelo homem, tanto no tempo quanto no espaço, em decorrência de sua manifesta vocação para transformar o meio natural. Nas palavras de Maurício Waldman:

Fenômeno que perpassa o tempo histórico, o lixo igualmente impregna o espaço habitado do homem. Engendrando formas nem sempre reconhecidas pelo nosso olhar, os resíduos marcaram indelevelmente a paisagem. Primeiramente, pelo fato de integrarem o processo mais amplo de transformação dos recursos naturais, seriam, nesta linha de argumentação, inseparáveis do dinamismo geral de construção do espaço. Em segundo lugar, concentrando-se ou dispersando-se em áreas circunscritas, os resíduos se associam à gênese de formas espaciais inéditas. Na sequência, podem condicionar fluxos responsáveis pela organização do espaço geográfico. (WALDMAN, 2010, p. 11).

O lixo gerado, tido como algo indesejável, demanda descarte. Os restos aqui considerados estão vinculados ao seu contexto histórico; não há como dissociá-los dele. O que é passível de descarte atende ao que determinam as expectativas socioculturais das populações. E o que se determina como passível de descarte em determinado tempo, por determinada população, poderá ser aproveitado por uma população distinta, a partir de seu universo cultural. Existem diferentes modos de percepção cultural e gerenciamento de refugos. A ideia do que é sujo, impuro, inútil, fétido e, por vezes, velho, determinará aquilo a ser descartado.

As cidades buscaram soluções para a questão do lixo, mas o crescimento do conhecimento científico sobre a saúde humana e as implicações das condições sanitárias ofereceram com maior força o impulso para o aperfeiçoamento das técnicas de coleta e destinação dos dejetos. O lixo produzido assume características diferentes a partir de influências sociais e condicionantes naturais.

Inúmeros são os fatores que exercem influência sobre as características do lixo produzido e a forma como se lida com ele: posição geográfica, clima, disponibilidade de água, tipo de solo, modo de produção, distribuição de riquezas, religião e concepção de vida e morte (EIGENHEER, 2009). A avaliação aqui descrita deve ser considerada em vista do aumento da população nos centros urbanos, o que provoca um considerável aumento das demandas dos serviços públicos e pressiona o crescimento de suas estruturas, resultando consequentemente em uma reconfiguração a partir da adoção de técnicas específicas, condizentes com as especificidades de cada região.

O problema de coleta e da destinação final do lixo implicou ações governamentais em diversas cidades, algumas datadas do século XIII. Na cidade do Rio de Janeiro, o problema também é antigo. Condições insalubres favoreciam o surgimento de moléstias e colaboravam para um cenário degradante. As práticas de descarte do lixo eram parecidas com as de outras capitais europeias. O lixo era atirado para fora de casa ${ }^{6}$ e, geralmente, tinha como destino natural os alagados, charcos e pântanos.

4 Panorama dos resíduos sólidos no Brasil, 2013.

5 Instituto Pereira Passos, 2014.

6 As águas servidas eram lançadas pelas janelas, um hábito generalizado. 
Um provimento de correição datado de 1735, por meio do Ouvidor Geral, Corregedor, Provedor da Comarca, advertia que:

Convém muito a saúde desta cidade que a Valla que nella se fez da lagoa da Ajuda para a Prahinha esteja sempre dezempedida para correrem por ella livremente as agoas e para que assim se conserve, mandou que nenhuma pessoa de qualquer coalidade e condição que seja, lance, nem mande lançar nella entulho, lixo, varridoras, emmundicie nem outra algua couza que possa embaraçar o curso das agoas, pena de ser condenado o que for compreendido; sendo escravo em açoutes e dois mezes de gallés por cada vez e sendo livre em vinte mil réis, para as despesas do aconselho acusador. (AIZEN e PECHMAN, 1985, p. 18).

Uma providência para minimizar as consequências do lançamento das imundícies pelas janelas foi o armazenamento dos dejetos em barris ou recipientes semelhantes ${ }^{7}$. Quando cheios, a remoção era realizada por escravos e geralmente à noite. O material era, na maioria das vezes, destinado ao mar.

A ausência de transporte promovia a aglutinação de moradias no Rio de Janeiro. Todos moravam juntos, apesar da distinção das casas entre os ricos e pobres. A separação acontece posteriormente, com a introdução dos meios de transporte. Os bondes com tração animal, como também o trem a vapor, tornaram-se ponto de partida para a expansão urbana do Rio de Janeiro e seu respectivo crescimento físico. Ressalta-se que, no período, a maior parte da população era escrava. Poucos trabalhavam livremente e um grupo ainda menor compunha a classe dirigente. Os bairros servidos por bondes tornaram-se destinos para as classes "nobres" e o subúrbio para as classes menos privilegiadas, incluindo os "usos sujos".

$\mathrm{Na}$ segunda metade do século XIX, o imperador D. Pedro iI assinou um contrato básico para esgotamento sanitário para a cidade do Rio de Janeiro com João Frederico Russel e Joaquim Pereira Vianna. O objetivo era construir e administrar uma rede pública de esgotos sanitários, incluindo a instalação de esgotos em prédios da área central. A elaboração do projeto ficou por conta de Eduardo Gotto, após constituir uma empresa de capital inglês, The Rio de Janeiro City Improvements Company Limited, ligada à Gleen and Mills. Em 1863, após a transferência do contrato de João Russel e Joaquim Vianna, a City se encarregou de construir e manter a rede de águas pluviais dos distritos localizados na área central.

Quanto aos serviços de limpeza urbana, após várias iniciativas de consolidação de um contrato para a coleta e transporte de lixo, a Junta Central de Higiene Pública noticia a contratação dos serviços de Aleixo Gary, em 1876. O trabalho de coleta de lixo nas casas era realizado por carroceiros. O lixo de toda a cidade era concentrado à beira-mar para despejo em barcaças e remoção para Sapucaia.

A ilha de Sapucaia, que recebeu lixo durante os séculos XIX e Xx, juntamente com outras oito ilhas (Santo Antônio, Bom Jesus, França, Ferreira, Catalão, Cabras, Baiacu e Fundão) formaram uma só ilha, a Ilha do Fundão, após o aterramento. O procedimento adotado se assemelha ao que fora adotado em Londres. Os rejeitos eram transportados por via marítima (pelo rio Tâmisa) a Essex para o aterramento dos pântanos daquela região.

A estrutura criada para a execução do serviço de limpeza pública, limpeza das praias e coleta de lixo nas casas contava com varredores e coletores. O transporte era realizado por carroças que transportavam o lixo até pontos de transferência para barcaças, que destinavam o lixo, por via marítima, a Sapucaia.

O destino final do lixo continuava a ser um problema para a cidade. Os dejetos, que por vezes retornavam para o litoral em decorrência da atuação das marés sobre os resíduos lançados ao mar ou oriundos de Sapucaia, aumentavam o trabalho de limpeza das praias, somando-se à quantidade de lixo já disposta na ilha. Pontos de transferência do lixo na Baía de Guanabara evidenciam modelos técnicos adotados para a coleta e destinação.

A situação era grave. Além da deficiência do transporte pelo mar e da poluição da Baía com o lixo despejado, a Ilha de Sapucaia já estava transbordando de lixo. Só no mês de novembro de 1883 foram incinerados, na ilha, 10.448 cadáveres de animais. O movimento do lixo para as diversas estações receptoras e destas para Sapucaia, onde era incinerado, foi de 12.674 carroças, 451 saveiros e 1.379 escaleres com o peso geral de 11.181.414 kg (AIZEN e PECHMAN, 1985).

A destinação do lixo para a Ilha de Sapucaia foi iniciada em 1865. A ilha foi local de despejo até o

7 A maioria dos recipientes era feita com madeira e se decompunha facilmente. 
ano de 1949, quando o lixo passou a ser enviado para o aterro do Retiro Saudoso, Camorim. O lançamento ao mar se manteve como prática bastante utilizada.

Durante o governo do Prefeito Pereira Passos (1903-1906) houve uma enorme transformação urbanística no Rio de Janeiro. Naquela época, o processo mais utilizado para a destinação do lixo ainda era o vazadouro no mar, nos aterros do Amorim e do Retiro Saudoso (Caju). Preocupado com o saneamento e a higiene, segundo Abreu (2013), o prefeito promoveu a canalização de alguns rios e o saneamento de parte da Lagoa Rodrigo de Freitas e determinou que o lixo fosse removido para a Ilha de Sapucaia.

Em 1906, a população do Rio de Janeiro girava em torno de 800 mil habitantes. O serviço de limpeza urbana dispunha de 1.084 animais, já insuficientes para a limpeza da cidade, que produzia 560 toneladas de lixo.

Em 1904, a Superintendência consolida a estrutura organizacional dos serviços de limpeza urbana da cidade. Algumas medidas inovadoras foram adotadas pelo Departamento, como o uso de caminhões coletores compactadores, até hoje utilizados, e a introdução, junto à população, do hábito de embalar o lixo em sacos, além da utilização de uniformes oficiais da prefeitura. Apesar das medidas, a coleta não atendia toda a população, negligenciando principalmente as favelas que se erguiam.

$\mathrm{Na}$ administração de Antônio Prado Júnior, por meio do Plano Agache ${ }^{8}$, foi proposta a proibição de favelas nas áreas nobres da cidade por diversos motivos, entre os quais a alegação de que a população era avessa a toda e qualquer regra de higiene. Construídas sem planejamento, as favelas não atendiam aos preceitos de higiene, pois não havia canalização de água, esgotos e serviços de limpeza pública.

Os meios de transporte adotados para a coleta do lixo incluíam uma frota de caminhões destinada exclusivamente para esta finalidade, como também bondes. Em ocasiões de aquisição de veículos, a apresentação era realizada por meio de solenidades.

A superintendência de limpeza pública transforma-se em Departamento de Limpeza Urbana em 1940. Houve a promoção de diversas campanhas de limpeza pública por meio de cartazes. Com o slogan "É mau hábito...", a defesa das ações de conservação advertia sobre os perigos do descarte das sobras de comida e de outros dejetos, do uso de terrenos baldios para despejo do lixo e, ainda, aplicava multas a quem lavasse calçadas fora do horário estipulado por autoridade pública e outras medidas punitivas por atos não higiênicos.

A expansão urbana do Rio de Janeiro foi influenciada pela extensão das linhas de bonde, das linhas férreas e, a partir de meados do século $\mathrm{xx}$, das estradas. A demanda por coleta de lixo acompanhou essa dinâmica. A construção da Av. Brasil permitiu, posteriormente, a destinação dos resíduos para ainda mais longe da cidade. A partir de então, o lixo atravessou a área limítrofe do município. Apontado por Maurício de Abreu (2013), o aumento do fluxo migratório em direção à capital da República no período 1940-1950, movimento ainda maior nos anos 1950 devido ao aumento populacional, pressionou de forma contundente a demanda por serviços de limpeza.

A fusão do Estado do Rio de Janeiro e da Guanabara em julho de 1974 estabeleceu a Região Metropolitana do Rio de Janeiro, constituída dos seguintes Municípios: Rio de Janeiro, Niterói, Duque de Caxias, Itaboraí, Itaguaí, Magé, Maricá, Nilópolis, Nova Iguaçu, Paracambi, Petrópolis, São Gonçalo, São João do Meriti e Mangaratiba (Lei complementar n ${ }^{\circ} 20,1^{\circ}$ de julho de 1974).

A fim de atender às demandas por soluções técnicas para o equacionamento dos problemas da região metropolitana, entre outras responsabilidades, foi criada a FUNDREM (Decreto lei 18/1975).

A FUNDREM fomentou a elaboração e a atualização do Plano de Desenvolvimento Integrado da região metropolitana do Rio de Janeiro com a programação e execução dos serviços comuns e com a coordenação da execução de programas e projetos de interesse da mesma região, por meio de convênios ou contratos, e favorecendo a escolha de solução partilhada para destinação do lixo.

A Companhia Estadual de Limpeza Urbana (CELURB), do antigo Estado da Guanabara, se transforma em Companhia Municipal de Limpeza Urbana (COMLURB), e assume a administração e os serviços públicos de limpeza urbana do Município do Rio de Janeiro (Decreto Lei 102/1975). A COMLURB assumiria, especialmente, as obrigações e direitos oriundos de contratos celebrados pela CELURB para a realização de obras e serviços, ficando responsável por sua execução e liquidação.

8 Plano urbanístico para a cidade do Rio de Janeiro elaborado sob a orientação de Alfred Agache, em 1927. 
Nos anos 1970, havia problemas para a destinação final dos resíduos sólidos urbanos gerados pela população e o esgotamento de lixões demandava um redirecionamento do fluxo do lixo. A necessidade de um novo local para despejo criou condições para o estabelecimento, em 1976, de um convênio entre a Companhia de Limpeza Urbana (COMLurB), a Fundação para o Desenvolvimento da Região Metropolitana (FUndRem) e a Prefeitura Municipal de Duque de Caxias para a definição de um local de descarte do lixo em Jardim Gramacho, localizado no município de Duque de Caxias (RJ).

A construção da Av. Brasil ${ }^{9}$ possibilitou a destinação do material coletado pela companhia de limpeza urbana para o aterro do Jardim Gramacho, que iniciou suas atividades no ano de 1978 como um aterro metropolitano, e atendeu também à demanda de descarte de lixo de outros municípios da região ao longo de sua vida útil. No início, recebia cerca de 2.000 toneladas por dia. Utilizado durante 36 anos, recebia ao fim de sua vida útil, em 2012, em média 8.00o toneladas por dia.

O aumento da geração de lixo associado à expansão urbana e ao aumento populacional demandou a operacionalização de outro aterro sanitário. Em 1987, entrou em operação o Aterro de Gericinó, localizado no bairro de Bangu, Rio de Janeiro (RJ). Além desses dois grandes aterros, outros menores recebiam lixo: Jacarepaguá e Santa Cruz.

Um Centro de Pesquisa Aplicada possuía um laboratório de microbiologia e, como parte do trabalho, deu início à análise do biogás gerado no $\mathrm{Caju}^{10} \mathrm{e}$ à implantação do processo de aproveitamento deste para veículos leves em 1985 . No ano seguinte, 1.200 veículos para transporte de resíduos utilizavam biogás para o abastecimento de parte da frota. Ao fim dos anos 1980, a COMLUR B contava com máquinas pesadas, basculantes, carretas, poliguindastes, varredeiras mecânicas e caminhões-pipa, além de caminhões de coleta.

No início dos anos 1990, o Rio de Janeiro totalizou, entre coleta de lixo domiciliar ${ }^{11}$ e de lixo público $^{12}$, aproximadamente 1.715.518 toneladas. Entre 1990 e 1999, o lixo público coletado no município cresceu rapidamente, atingindo o ápice em 1996. Nesse ano, o número excedeu um milhão de toneladas coletadas. Houve queda nos dois anos seguintes, quando então o montante tornou a crescer, atingindo 997.786 toneladas coletadas e destinadas aos aterros disponíveis. O total coletado em 1999 ( 999.786 toneladas) foi mais que o dobro do que aquele coletado em 1990 (479.349 toneladas).

Em 1994, o serviço de coleta de lixo domiciliar e público passou a ser realizado também no período noturno, aumentando a capacidade de captação dos resíduos no município. Isso promoveu uma diferença considerável na evolução do total coletado nos domicílios e nas áreas públicas do município do Rio de Janeiro e destinado para os aterros disponíveis. No geral, o volume de lixo gerado e coletado para destinação aos lixões, nesse período, segue uma linha de crescimento contínuo. Maurício Waldman (2010) observa que a aceleração do descarte do lixo domiciliar transcorre par a par com a velocidade que caracteriza a produção e o consumo de mercadorias na modernidade.

Considerando-se que o crescimento populacional do Rio de Janeiro foi influenciado pelo movimento migratório, como já demonstrado no texto por intermédio de Maurício de Abreu, o município tem, no ano de 1990, uma população de 5.442.424 habitantes, resultando numa média de 315,21 kg/ hab. e crescendo para 439,62 kg/hab. em função de um total populacional de 5.598.955 habitantes.

O crescimento do total de lixo coletado ao longo dos anos 1990 foi determinante para o esgotamento dos pontos de descarte do município. No período, mesmo com o funcionamento dos aterros de Gramacho e Gericinó, o município do Rio de Janeiro ainda utilizava os aterros de Jacarepaguá e Santa Cruz, que compunham as alternativas para descarte. Não havia investimentos específicos para a construção de novos aterros por parte da Companhia de Limpeza Urbana (COMLURB).

A decisão de modificar o cenário negativo por conta da ausência de uma solução definitiva para o confinamento do lixo aconteceu em meados dos anos 1990. No Jardim Gramacho e em Gericinó foram adotados novos processos técnicos e operacionais com vistas à obtenção de um maior controle sobre o maciço de lixo.

Com a aproximação do fim da vida útil dos dois aterros sanitários em funcionamento, houve

9 Construída em 1946, conectando as antigas Rio-São Paulo e Rio-Petrópolis.

10 Principal destino do lixo entre os anos de 1940 e 1970. Atualmente é uma estação de transferência.

11 Resíduos originários da coleta em domicílios no município.

12 Resíduos originários do serviço público de limpeza. 
desmoronamento no Gramacho (local construído sobre terreno com argila de baixa resistência mecânica ${ }^{13}$ que, a partir de então, passou a ser monitorado por uma empresa de geotecnia). Aumentou a urgência por um novo local para a construção de uma Central de Tratamento de Resíduos (CTR). As condições de estabilidade do aterro se mostravam deterioradas, e estudos técnicos apontavam o fim de sua vida útil para o ano de $2004^{14}$.

No início do século XXI, a geração de resíduos crescia consideravelmente. Os dados da companhia de limpeza urbana estimam uma geração de quase 10 mil toneladas por dia. Em 2009, a distribuição dos valores gerados, considerando-se todo o município do Rio de Janeiro, reflete a geração média per capita de aproximadamente $1,5 \mathrm{~kg}$ por habitante, a cada dia.

Total de Resíduos Sólidos Urbanos (RSU) coletados entre os anos de 2000 e 2009 no município do Rio de Janeiro

\begin{tabular}{|l|c|c|c|}
\hline Ano & Lixo público coletado & $\begin{array}{c}\text { Lixo domiciliar } \\
\text { coletado }\end{array}$ & $\begin{array}{c}\text { Total de RSU no } \\
\text { município do Rio de } \\
\text { Janeiro }\end{array}$ \\
\hline 2000 & 967.313 & 1.439 .526 & 2.406 .839 \\
\hline 2001 & 1.039 .698 & 1.425 .176 & 2.464 .874 \\
2002 & 1.242 .778 & 1.451 .954 & 2.694 .732 \\
\hline 2003 & 1.306 .225 & 1.385 .929 & 2.692 .154 \\
2004 & 1.196 .024 & 1.445 .490 & 2.641 .514 \\
\hline 2005 & 1.257 .678 & 1.460 .716 & 2.718 .394 \\
\hline 2006 & 1.285 .962 & 1.508 .574 & 2.794 .536 \\
2007 & 1.315 .377 & 1.513 .533 & 2.828 .910 \\
\hline 2008 & 1.282 .449 & 1.576 .935 & 2.859 .384 \\
\hline 2009 & 1.286 .443 & 1.589 .344 & 2.875 .787 \\
\hline
\end{tabular}

Lixo público coletado: total de resíduos coletados oriundos da execução do serviço de limpeza urbana em área pública do município no período de referência, como varrição, poda, capina e outros;

Lixo domiciliar coletado: total de lixo coletado em residências do município no período de referência;

Total de RSU: resultante da soma de lixo público e domiciliar coletado no ano de referência.

Nota: Há um quantitativo de resíduos sólidos urbanos não considerados na tabela. Os números referentes aos resíduos emergenciais e outras remoções gratuitas não são significativos.

Fonte: O autor, a partir de dados do InSTITUTO PEREIRA PASSOS, 2015.

Entre os anos de 2000 e 2009, o total de lixo público coletado para destinação final pela companhia de limpeza pública no município do Rio de Janeiro ultrapassou os 12 milhões de toneladas. A partir do ano de 2001, o quantitativo ultrapassou o número de um milhão de toneladas para não mais cair nos anos seguintes.

Em 2009, a disposição do lixo coletado e destinado para confinamento no município do Rio de Janeiro demandava meios técnicos para aproximadamente 2.900.00o toneladas - um cenário crítico em vista do fim da vida útil dos aterros disponíveis ao município.

O processo de encerramento das atividades no aterro Gramacho acontecia ao mesmo tempo em que se resolviam pendências administrativas ${ }^{15}$ com a empresa vencedora da licitação para a implantação do aterro no bairro de Paciência.

A enorme quantidade de ações judiciais que questionavam a implantação do cTR Rio foi causa de paralisações do processo construtivo e, posteriormente, de sua suspensão definitiva. Houve pressão por parte dos moradores do entorno da área definida para o aterro. A rejeição foi evidenciada durante seis audiências públicas realizadas, bem como nos questionamentos judiciais em instâncias estaduais e federais ${ }^{16}$.

13 Implantado sobre manguezal às margens da Baía de Guanabara.

14 O Aterro Metropolitano de Jardim Gramacho teve sua vida útil estendida até o ano de 2012.

15 Mapa de conflitos envolvendo injustiça ambiental e saúde no Brasil - Moradores lutam contra a instalação de aterro sanitário.

16 Decreto Municipal 30.341/2004. 
Os principais argumentos para a inviabilidade da implantação do aterro no bairro de Paciência foram: fragilidades apresentadas no projeto, insuficiência para receber o volume contratado no terreno escolhido ${ }^{17}$, riscos de contaminação do lençol freático por ausência de segurança ambiental para tratamento de efluentes ${ }^{18}$, localização do terreno em área de proteção permanente (dentro da área de segurança aeroportuária da base de Santa $\mathrm{Cruz}^{19}$ ) e questionamentos quanto à legalidade da criação de Área de Especial Interesse Funcional por meio de Decreto Municipal ${ }^{20}$, ao contrário de uma Lei Complementar, o que culminou na sustação do decreto por meio de Decreto Legislativo ${ }^{21}$.

O contrato permitia ao vencedor, mantidas as condições contratuais, a instalação do aterro em local diferente do que fora inicialmente licitado. Um grupo de trabalho constituído para solucionar o problema da destinação e tratamento dos resíduos sólidos da cidade do Rio de Janeiro considerou necessário aproveitar o contrato vencedor em local, pela convocação da empresa vencedora para que apresentasse um novo local capaz de atender às condições necessárias ao projeto.

O projeto CTR Rio adquire importância para o novo cenário nacional de política de gestão de resíduos sólidos diante dos riscos que o prolongamento da vida útil do principal aterro utilizado pelo município oferecia. O aterro de Gramacho, ao fim dos primeiros dez anos deste século, operava no limite de sua capacidade operacional.

A construção da infraestrutura necessária para orientar o novo fluxo dos resíduos sólidos urbanos para o município do Rio de Janeiro resultou na execução do projeto em questão. A área então escolhida foi uma região rural do município de Seropédica, antiga fazenda de gado, com aproximadamente 2,2 milhões de $\mathrm{m}^{2}$. Há, na vizinhança, uma pedreira, uma usina de asfalto, unidades de mineração de areia, além de diversas chácaras e sítios ao redor do empreendimento. Ao contrário de Gramacho, o aterro conta com um sistema de impermeabilização e um sistema de drenagem para águas pluviais, de gases e de chorume, além de uma estação de tratamento dos líquidos percolados. A área receberá, durante sua vida útil, entre nove e dez mil toneladas de resíduos sólidos urbanos por dia.

\section{A REDE DOS RESÍDUOS SÓLIDOS URBANOS DO MUNICÍPIO DO RIO DE JANEIRO NO SÉCULO XXI: O EXEMPLO DA EMPRESA CICLUS ${ }^{22}$}

No município do Rio de Janeiro, no início do século XXI, com a construção da Central de Tratamento de Resíduos (CTR Rio), houve um reordenamento do fluxo de resíduos sólidos urbanos. Unidades de recepção e transferência foram criadas, promovendo, por consequência, um novo fluxo de resíduos sólidos urbanos para destinação final.

No ambiente complexo de inúmeras redes urbanas, dos mais variados padrões espacias que interagem no espaço, emerge como fração deste conjunto uma nova rede geográfica orientadora do destino final dos resíduos sólidos coletados no município do Rio de Janeiro, acatando para fins de ordenamento desta rede sua divisão administrativa, ou seja, suas áreas de planejamento. As áreas de planejamento do município são aqui apresentadas como localizações geográficas conectadas por diversos fluxos, entre os quais destacamos os de destinação final de resíduos sólidos urbanos, formados a partir da implantação da CTR Rio, sob responsabilidade administrativa da empresa Ciclus.

Ancorados no entendimento de Corrêa, apropriamo-nos de sua argumentação, que diz:

Por rede geográfica entendemos "um conjunto de localizações geográficas interconectadas" entre si "por um certo número de ligações". Este pode ser constituído tanto por uma sede de cooperativa de produtores rurais e as fazendas a ela associadas, como pelas ligações materiais e imateriais que conectam a sede de uma grande empresa, seu centro de pesquisa e desenvolvimento, suas fábricas, depósitos e filiais de venda. Pode ser constituído por agências de um banco e os fluxos de informações

17 Ação ordinária 2003.001.061799-6.

18 Processo 40/001170/2005 - ONG Grupo de Defesa Ambiental.

$193^{\circ}$ COMAR - Comando Aéreo Regional - Ofício n² 27/SRE3/1075.

20 Decreto Municipal 24710/2004.

21 Decreto Legislativo 602/2007.

22 Nome fantasia para Saneamento e Energia Renovável do Brasil. 
que circulam entre elas. Pela sede da Igreja Católica, as dioceses e paróquias, ou ainda pela rede ferroviária de uma dada região. Há, em realidade, inúmeras e variadas redes que recobrem, de modo visível ou não, a superfície terrestre. (CORRÊA, 2010, p. 107).

A rede geográfica aqui apresentada se constitui de um aterro sanitário conectado às suas estações de transferência que, por sua vez, são receptoras do lixo público e domiciliar coletado em todo município do Rio de Janeiro a partir do ano de 2011.

Em 1981, para fins de planejamento e coordenação, a administração municipal definiu Áreas de Planejamento, Regiões Administrativas e o bairreamento com seus respectivos limites oficiais.

As Estações de Transferência (ETR), como são conhecidas, estão localizadas em pontos estratégicos do município para, além de colaborarem com o transporte, diminuírem o tempo entre o instante da coleta e o descarte no destino final, a Central de Tratamento de Resíduos (CTR).

As estações são dotadas da infaraestrutura necessária aos fluxos de drenagem dos resíduos sólidos domiciliares e dos espaços públicos, suas posições geográficas são estratégicas e estão interconectadas por meio de ruas e das principais avenidas, de modo a favorecer a recolha nas regiões administrativas do município, contemplando todas as áreas de planejamento.

A coleta dos resíduos sólidos urbanos no município do Rio de Janeiro contou, a partir de 2011, com veículos de menor porte para a recepção dos resíduos coletados que, posteriormente, prosseguem ao destino final por meio de carretas com capacidade elevada de carga.

A geração de resíduos sólidos urbanos na AP.1 (Tabela 1) é de 734 toneladas diárias para uma população de 208.267 habitantes, o que equivale a aproximadamente $3 \%$ da população do município e corresponde ao total de $8 \%$ dos resíduos gerados diariamente (cerca de 3,96 kg/hab./dia).

Tabela 1: Descrição da geração de resíduos per capita ${ }^{23}$ por Área de Planejamento do município do Rio de Janeiro - AP.1

$\begin{array}{lc}\text { População (hab.) } & 208.267 \\ \text { \% População } & 3,0 \\ \text { Geração (t/dia) } & 734 \\ \text { \% Resíduos } & 8,0 \\ \text { Geração per capita (kg/hab./dia) } & 3,96 \\ \text { Fonte: adaptada do PMGIRs da Cidade do Rio de Janeiro, 2012. }\end{array}$

Na AP.1 está concentrada a maior parte das atividades comerciais e de serviços. Se comparada às demais áreas, possui a primazia da rede instalada para drenagem dos resíduos, e sua geração per capita de resíduos é o dobro de outras três áreas e o triplo da AP5.

A geração de resíduos sólidos na AP.2 (Tabela 2) é de 1.526 toneladas diárias para uma população de 878.400 habitantes, o que equivale a aproximadamente $15 \%$ da população do município e corresponde ao total de $16 \%$ dos resíduos gerados diariamente (cerca de 2,o kg/hab/dia).

As duas áreas de planejamento destinam seus resíduos para a estação de transferência do Caju. O fluxo de destinação é rodoviário, conectado por ruas dos respectivos bairros e convergindo para Av. Brasil, no bairro do Caju.

A estação que recebe o maior volume coletado (de aproximadamente 900 caminhões coletores COMLUR B que descarregam lixo diariamente no local) é a ETR Caju. Inaugurada em 1992, ano em que foi realizada a Conferência de Meio Ambiente e Desenvolvimento Rio $92^{24}$, realiza a transferência diária de resíduos por meio de 170 viagens de carretas, aproximadamente.

23 O valor per capita é resultante do valor total de resíduos do município em função da população total estimada pelo Instituto Pereira Passos, em 2011.

24 Conferência das Nações Unidas sobre o Meio Ambiente e Desenvolvimento, realizada no Rio de Janeiro, em 1992. 
Tabela 2: Descrição da geração de resíduos per capita ${ }^{25}$ por Área de Planejamento do município do Rio de Janeiro - AP.2

$\begin{array}{lc}\text { População (hab.) } & 878.400 \\ \text { \% População } & 15 \\ \text { Geração (t/dia) } & 1526 \\ \text { \% Resíduos } & 16 \\ \text { Geração per capita (kg/hab./dia) } & 2,0\end{array}$

Fonte: adaptada do PMGIRs da Cidade do Rio de Janeiro, 2012.

A geração de resíduos sólidos na AP.3 (Tabela 3) é de 3.480 toneladas diárias para uma população de 2.198.528 habitantes, o que equivale a aproximadamente $37 \%$ da população do município e corresponde ao total de $36 \%$ dos resíduos gerados diariamente (cerca de 2,o kg/hab./dia).

Os resíduos são coletados nos bairros correspondentes e convergem para Av. Brasil, no bairro de Fazenda Botafogo, embora a estação receba o nome de Marechal Hermes em decorrência da vinculação à região administrativa na qual está inserida.

A ETR Marechal Hermes foi inaugurada em 2012. As carretas que de lá saem percorrem $51 \mathrm{~km}$ até chegarem ao destino final. A estação atende diariamente ao volume coletado por 390 caminhões coletores COMLURB, que é transferido para a CTR em 78 viagens.

Tabela 3: Descrição da geração de resíduos per capita por Área de Planejamento do município do Rio de Janeiro - AP.3

$\begin{array}{lc}\text { População (hab.) } & 2.198 .528 \\ \text { \% População } & 37 \\ \text { Geração (t/dia) } & 3480 \\ \text { \% Resíduos } & 36 \\ \text { Geração per capita (kg/hab./dia) } & 2\end{array}$

Nota: O valor per capita é resultante do valor total de resíduos do município em função da população total estimada pelo Instituto Pereira Passos, em 2011.

Fonte: adaptada do PMGIRs da Cidade do Rio de Janeiro, 2012.

A geração de resíduos sólidos na AP.4 (Tabela 4) é de 1.494 toneladas diárias para uma população de 893.852 habitantes, o que equivale a aproximadamente $15 \%$ da população do município e corresponde ao total de $15 \%$ dos resíduos gerados diariamente (cerca de $2,0 \mathrm{~kg} / \mathrm{hab} . / \mathrm{dia}$ ).

Tabela 4: Descrição da geração de resíduos per capita por Área de Planejamento do município do Rio de Janeiro - AP.4

$\begin{array}{lc}\text { População (hab.) } & 893.852 \\ \text { \% População } & 15 \\ \text { Geração (t/dia) } & 1494 \\ \text { \% Resíduos } & 15 \\ \text { Geração per capita (kg/hab./dia) } & 2\end{array}$

Nota: O valor per capita é resultante do valor total de resíduos do município em função da população total estimada pelo Instituto Pereira Passos, em 2011.

Fonte: adaptada do PMGIRS da Cidade do Rio de Janeiro, 2012.

25 O valor per capita é resultante do valor total de resíduos do município em função da população total estimada pelo Instituto Pereira Passos, em 2011. 
A geração de resíduos sólidos na AP.5 (Tabela 5) é de 2.432 toneladas diárias para uma população de 1.814.510 habitantes, o que equivale a aproximadamente $30 \%$ da população do município e corresponde ao total de $25 \%$ dos resíduos gerados diariamente (cerca de 1,o kg/hab./dia).

Tabela 5: Descrição da geração de resíduos per capita por Área de Planejamento do município do Rio de Janeiro - AP.5

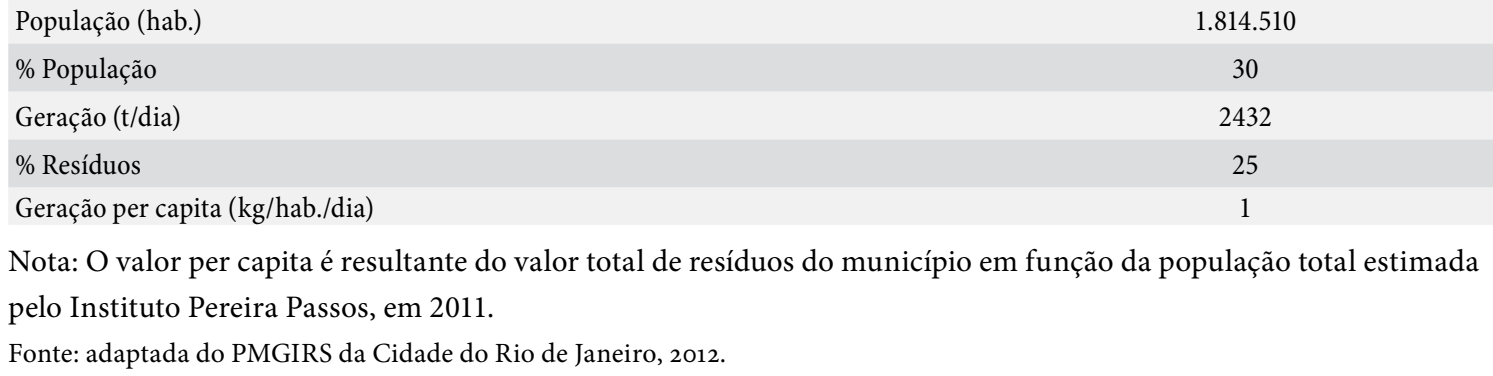

Nota: O valor per capita é resultante do valor total de resíduos do município em função da população total estimada pelo Instituto Pereira Passos, em 2011.

Fonte: adaptada do PMGIRS da Cidade do Rio de Janeiro, 2012.

Considerando os dados do ano de 2011 referentes às Áreas de Planejamento, o Plano Municipal de Gestão Integrada de Resíduos Sólidos no Rio de Janeiro indicou uma geração per capita de 1,6 kg, por dia, resultando em 9.666 toneladas.

O projeto CTR Rio contempla 7 (sete) Estações de Transferência de Resíduos para atender ao município, conforme a Tabela 6:

Tabela 6: Estações de transferência de resíduos sólidos urbanos em funcionamento e em fase de implantação no município do Rio de Janeiro

\begin{tabular}{llll} 
ETR & NOME & LOCAL \\
& Santa Cruz & Santa Cruz \\
Estações de Transferência em funcionamento & Jacarepaguá & Vargem Grande \\
& Gericinó & Bangu \\
& Marechal Hermes & Fazenda Botafogo \\
Estações de Transferência em fase de implantação & Caju & Caju \\
\hline
\end{tabular}

Legenda: Estação de Transferência de Resíduos (ETR); Nome: refere-se à gerência COMLURB da área em que está instalada.

Nota: As estações Tanque e Penha não possuem terreno definido para sua implantação.

Fonte: COMLURB.

A Estação de Transferência Santa Cruz, inaugurada em julho de 2012, está localizada na Estrada da Pedra e recebe diariamente 111 caminhões coletores CoMLur B carregados de resíduos dos bairros do seu entorno. Esses resíduos são transferidos para carretas que, em 28 viagens, percorrem aproximadamente $29 \mathrm{~km}$ até o destino final.

Localizada em Vargem Grande, a Estação de Transferência Jacarepaguá26, inaugurada em 1992, foi reformada no ano de 2014 para atender à demanda de 235 caminhões coletores COMLURB diariamente. A distância é de $58 \mathrm{~km}$ até destino final e o transporte se realiza por meio de carretas, em 45 viagens por dia.

Localizada na Av. Brasil, com 35 km de distância do destino final, a ETR Gericinó atende diariamente ao resultante de 247 caminhões coletores COMLURB. Inaugurada em 2014, dela partem aproximadamente 55 carretas, por dia, carregadas em direção à CTR.

26 As Estações de Transferência levam o nome da gerência comLurb à qual pertencem. 
Há duas Estações de Transferência ainda não construídas, em fase de implantação: ETR Tanque e ETR Penha. No momento de sua instalação e funcionamento, haverá um incremento da rede para coleta dos resíduos.

As estações estão instaladas em pontos geográficos estratégicos, apresentados no Mapa o1, de modo a favorecer a fluidez.

Mapa 01: Estações de Transferência de Resíduos (ETR)

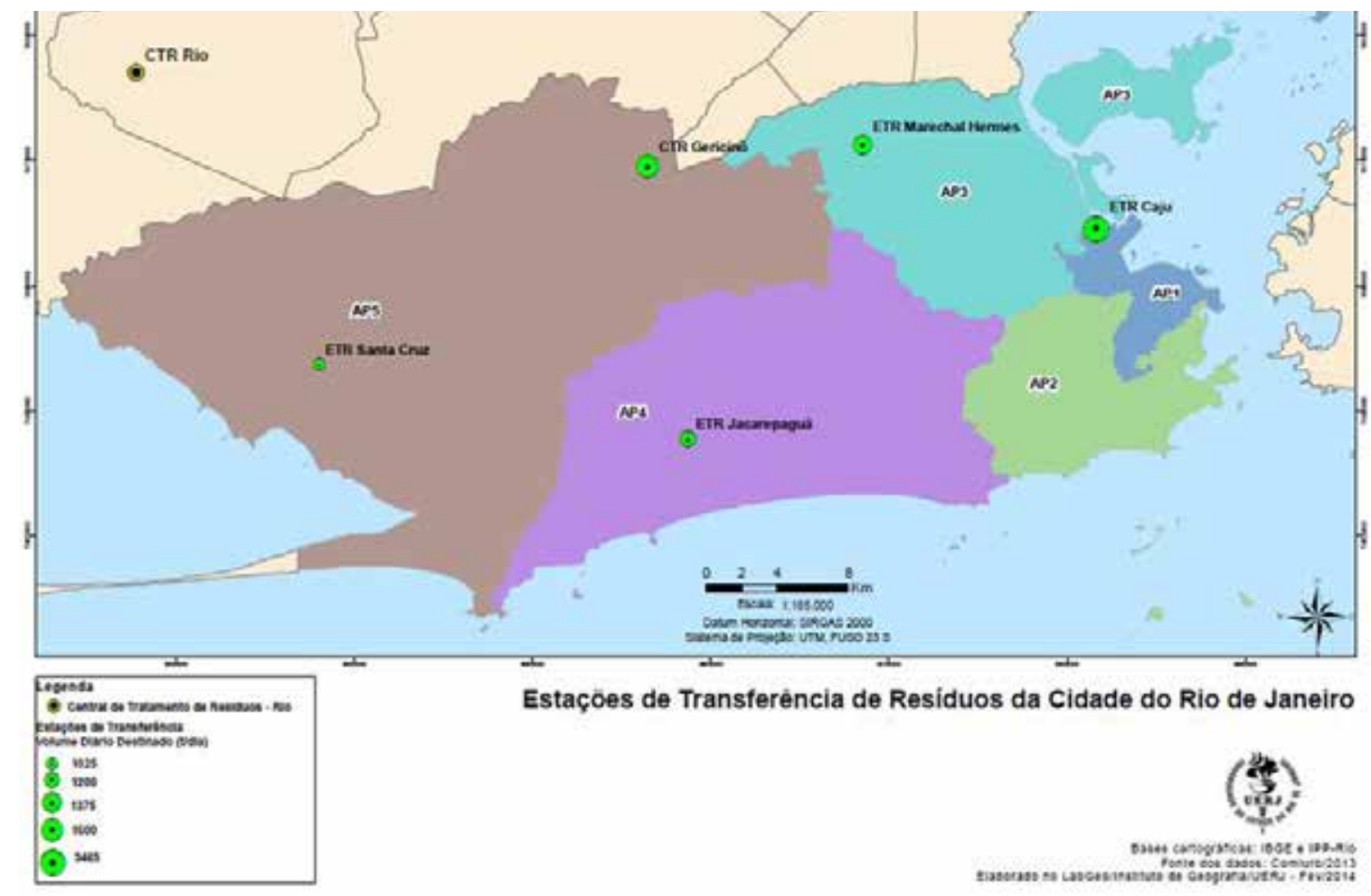

Fonte: $\mathrm{O}$ autor, 2014

A empresa gestora da Central de Tratamento de Resíduos iniciou sua operação em abril de 2014 (Figura 1) e está inserida no mercado de carbono pela utilização de Mecanismo de Desenvolvimento Limpo (MDL), utilizando instrumentos tecnológicos de captura de gás no aterro sanitário. Utilizou financiamento das instituições internacionais ${ }^{27}$ e aporte de recursos públicos, por meio de verbas federais do Fundo de Garantia do Tempo de Serviço (FGTS) ${ }^{28}$. Foi inserida no Plano de Aceleração do Crescimento (PAC) e apresentada entre o conjunto de obras de infraestrutura anunciadas como um legado da Copa do Mundo de 2014.

O total de Resíduos Sólidos Urbanos (RSU) coletado nos bairros do município do Rio de Janeiro é transportado para as Estações de Transferência instaladas nas Áreas de Planejamento e, em seguida, transferido para o município de Seropédica, onde está instalada a Central de Tratamento de Resíduos do Rio de Janeiro.

A CTR Rio recebe em sua área de operação, para o necessário confinamento dos resíduos, uma média de 9 mil toneladas por dia ${ }^{29}$ do município do Rio de Janeiro. O local é também o destino final do lixo para os municípios de Seropédica, Itaguaí e Mangaratiba. O empreendimento tem 15 anos como perspectiva de vida útil, com possibilidade de prorrogação por dois períodos de cinco anos.

27 Financiamento do Banco Mundial.

28 Financiamento da Caixa Econômica Federal.

Dados comlurb de 2013. 
Figura 1: Início da operação CTR Rio no município de Seropédica

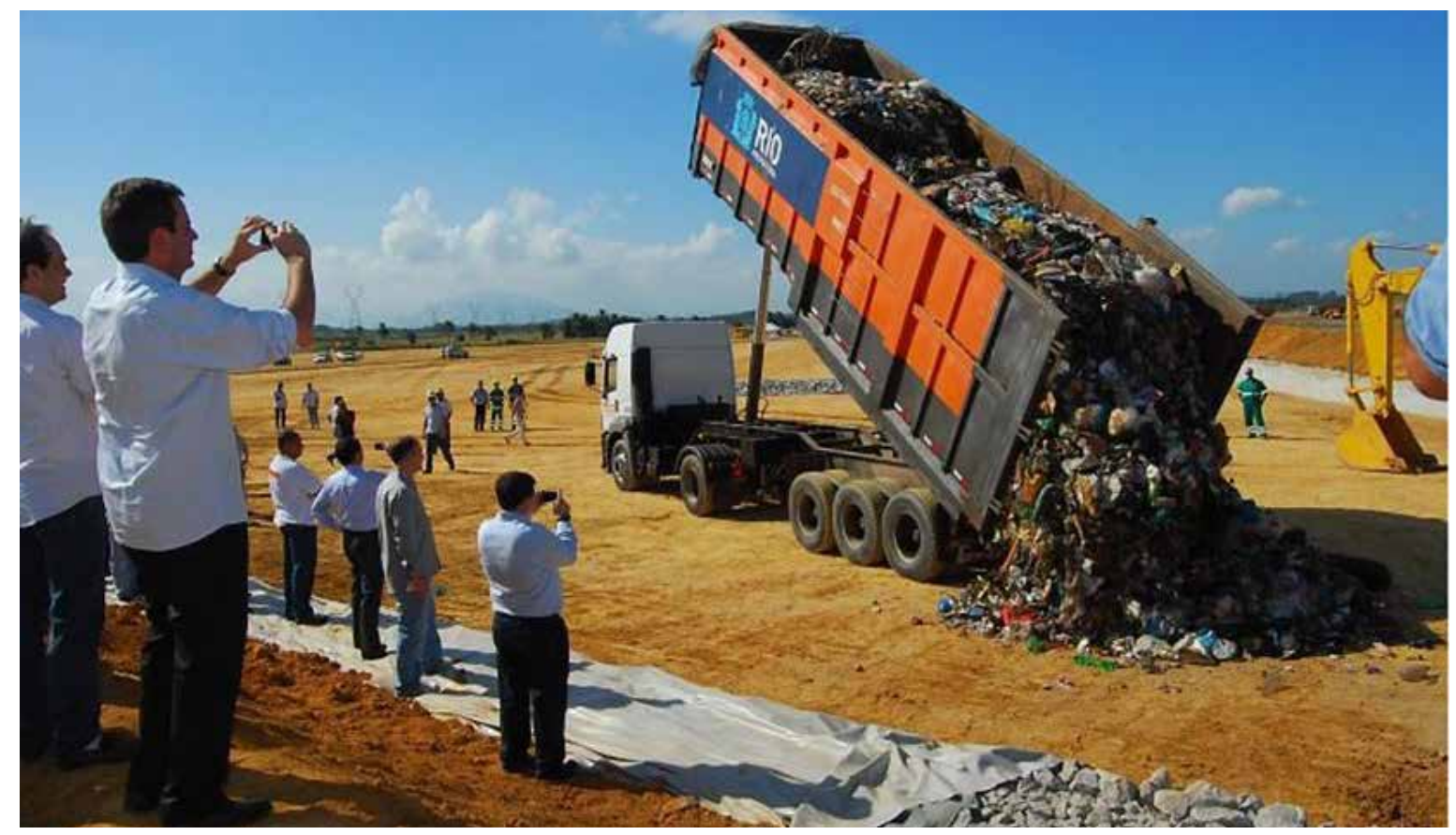

Fonte: <http://oglobo.globo.com/fotos/2011/o4/20/2O_MHG_RIO_2104_comlurb.jpg> (acesso em dez. 2014)

A Av. Brasil é a via coletora de todas as Estações de Transferência. Todo o Resíduo Sólido Urbano (RsU) coletado pela companhia municipal de limpeza (СOMLURB) utiliza a BR-101 para a destinação final.

Considerando como ponto de partida o bairro do Caju, a Av. Brasil recebe diariamente 3.465 toneladas de lixo oriundos da ETR desse bairro. A partir do bairro Fazenda Botafogo, por meio de um incremento de 1.600 toneladas da ETR Marechal Hermes, há um aumento considerável que se soma ao total de 1.375 toneladas da ETR Gericinó. A avenida recebe 6.440 toneladas/dia a partir do bairro Bangu.

O quantitativo coletado no município do Rio de Janeiro conflui para o bairro Santa Cruz. Neste ponto da Av. Brasil há o acréscimo de 2.225 toneladas/dia de resíduos oriundos da ETR Jacarepaguá e da ETR Santa Cruz (1.200 e 1.025 toneladas/dia, respectivamente).

Ao final da Av. Brasil, fluem diariamente aproximadamente 9 mil toneladas de Resíduos Sólidos Urbanos (RSU) coletadas no município do Rio de Janeiro, conforme o Mapa 2.

O fluxo segue em direção a Seropédica pela Rodovia Rio-Santos (BR-101), Reta de Piranema (RJ099) e, finalmente, Estrada de Santa Rosa (Figura 2).

A captação e a destinação dos resíduos sólidos urbanos no município são permanentes - ocorrem dia e noite, todos os dias do ano, resultando numa média de 9 mil toneladas diárias. Para tanto, um contingente de trabalhadores, utilizando as mais variadas técnicas e de posse dos instrumentos tecnológicos disponíveis, mantém um fluxo constante de transferência entre a geração e o destino final, colaborando para a organização espacial do município do Rio de Janeiro.

A organização espacial revela-se, por um lado, a partir de elementos fixos - não exclusivamente as cidades, mas também casa, porto, armazém, plantação, fábrica, constituídos como resultado do trabalho social e pelas forças produtivas engendradas pelo homem. E, por outro lado, através dos fluxos que garantem as interações entre fixos, parte integrante das redes (RIBEIRO, 2000).

A Central de Tratamento de Resíduos (CTR Rio), instalada no município de Seropédica, recebe o lixo captado pelas Estações de Transferência localizadas nas Regiões Administrativas (RAs) e inseridas nas Áreas de Planejamento (APS) que, por sua vez, recebem o lixo oriundo da limpeza realizada nos espaços públicos e nas residências de todos os bairros do município do Rio de Janeiro. 
Mapa 02: Total de lixo destinado diariamente à Central de Tratamento de Resíduos (CTR Rio)

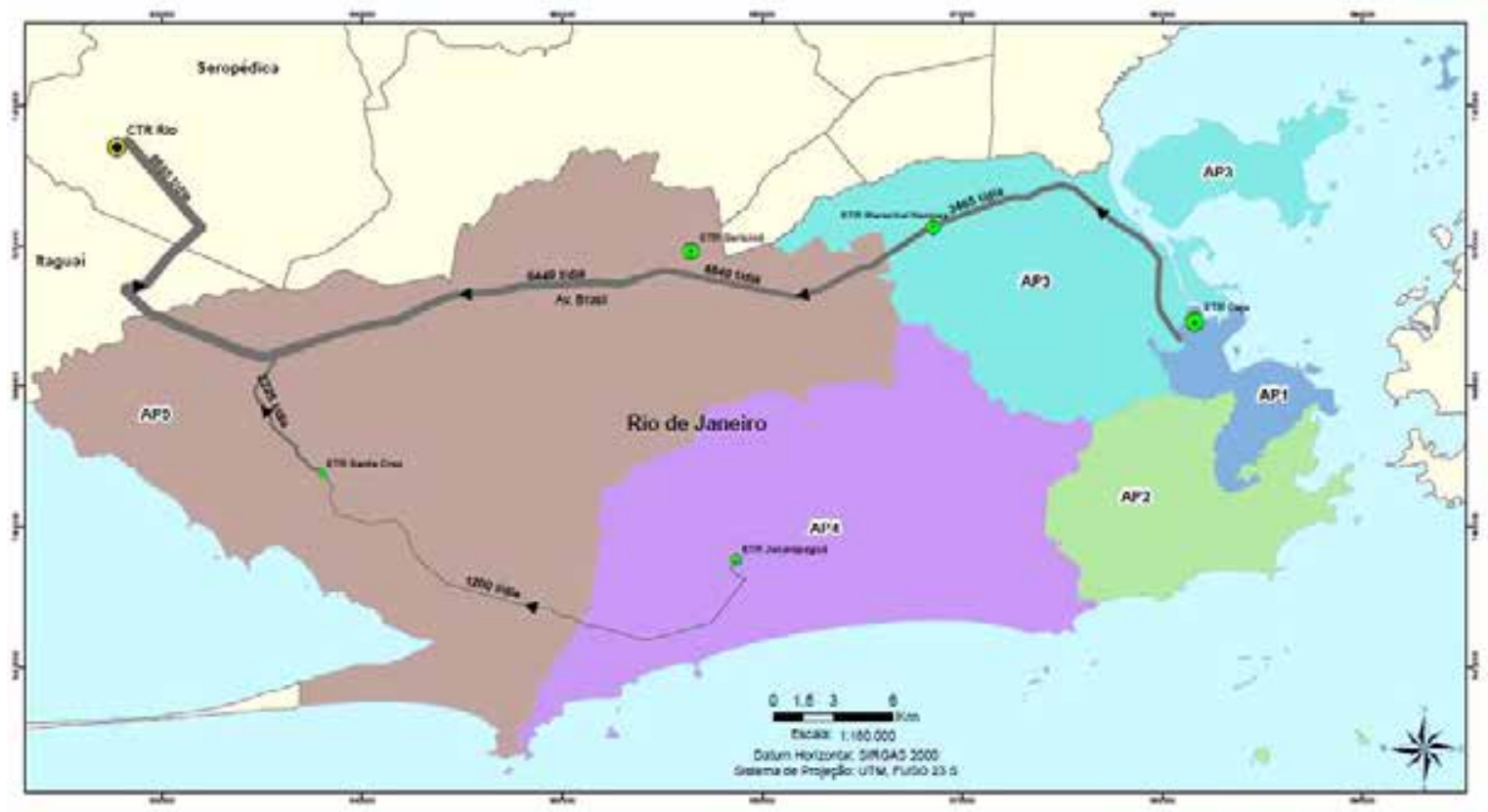

\begin{tabular}{|c|c|c|}
\hline \multicolumn{2}{|l|}{ Leopoda } & luxo \\
\hline $6 \sin \theta$ & Vias de Percunse & \\
\hline 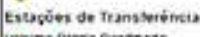 & 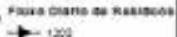 & Areas de Planejarnente \\
\hline 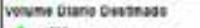 & $\rightarrow \pm$ & Less of Ranepantess 1 \\
\hline$x_{i}=1$ & $=$ & 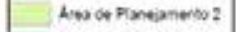 \\
\hline 8 & $\Rightarrow=4$ at+but & 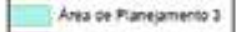 \\
\hline 6 nese & 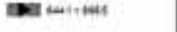 & 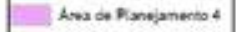 \\
\hline (2) sent & & Les de freneanenss \\
\hline
\end{tabular}

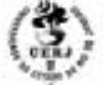

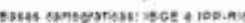

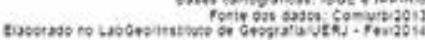

Fonte: $\mathrm{O}$ autor, 2014.

Figura 2: Vista aérea da CTR RIO

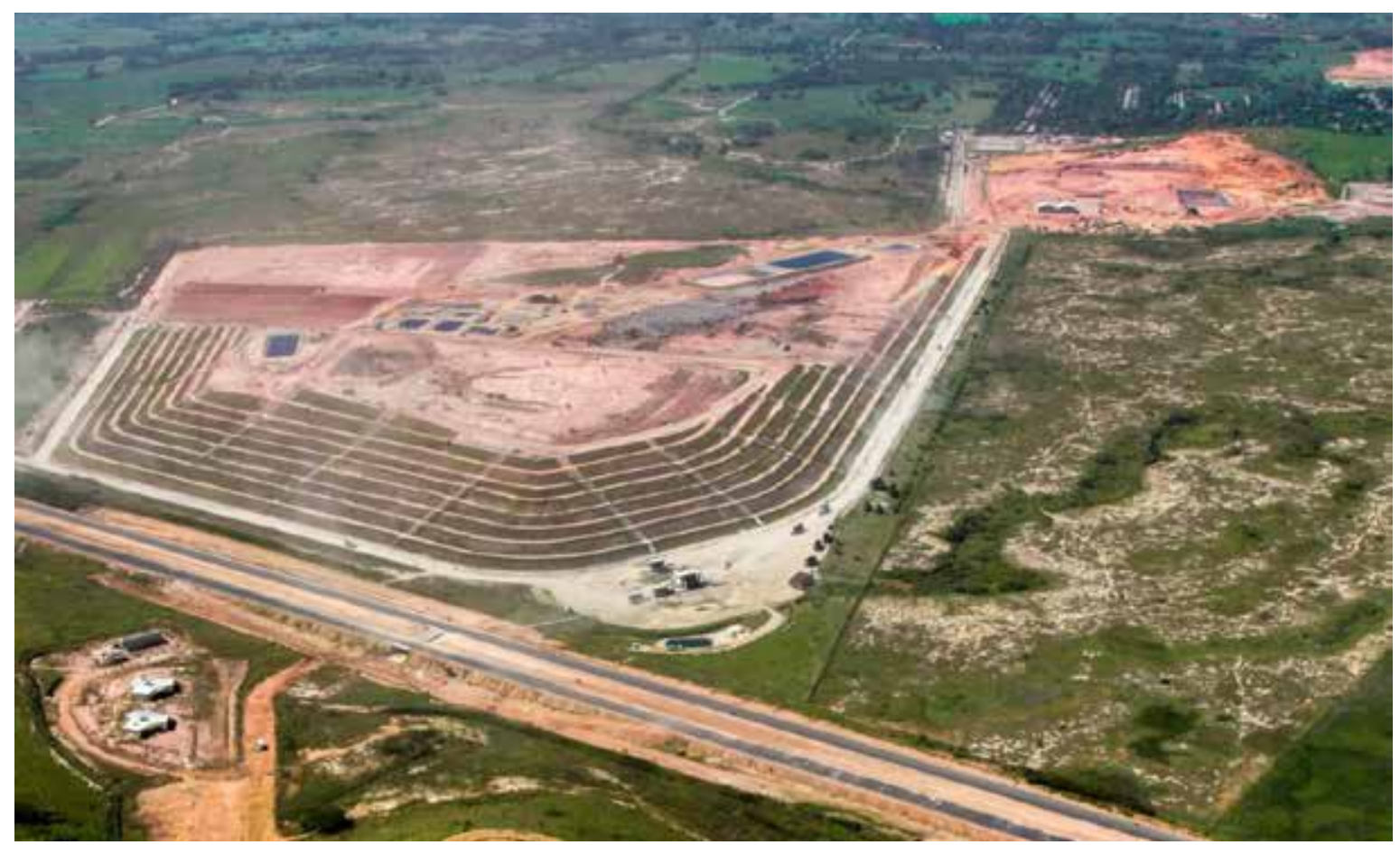

Fonte: Ciclus 
Importa afirmar que a malha rodoviária que permite a coleta de resíduos sólidos urbanos resulta em uma rede geográfica cujos fixos são representados pela Central de Tratamento de Resíduos (CTR Rio), Estações de Transferência (ETRs), equipamentos públicos e residências do município do Rio de Janeiro, conectados entre si e por onde circulam os fluxos - no caso, resíduos coletados segundo a logística da Companhia de Limpeza Urbana. Assim, temos como nós desta rede as estações de transferência e, como fluxo, o volume total de lixo coletados, como já demonstrado no Mapa 2.

\section{CONSIDERAÇÕES FINAIS}

O presente trabalho buscou identificar e analisar a nova rede geográfica instalada no município do Rio de Janeiro para coleta e destinação dos resíduos sólidos urbanos, que emergiu a partir do esgotamento dos aterros de Jardim Gramacho e Gericinó.

Há uma nova rede geográfica para destinação final dos resíduos sólidos urbanos do município do Rio de Janeiro. Antes do ano de 2011, a partir dos fixos, residências e equipamentos públicos e contando com menos da metade das estações de transferência que hoje estão instaladas, os resíduos coletados fluíam para duas áreas de confinamento. Estas não dispunham das condições de proteção ambiental adequadas, e também não atendiam à legislação, especificamente a lei 12.305, em vigor desde 2010, que institui a Política Nacional de Resíduos Sólidos Urbanos. Além disso, o fim da capacidade operacional em Gericinó e Gramacho promoveu a modificação. Hoje, temos o reordenamento dos fixos. Com o aumento do número de estações de transferência instaladas em pontos estratégicos e que favorecem a fluidez por meio da utilização das principais vias do município, há convergência do fluxo. Ao contrário da rede anterior, todo resíduo é destinado à CTR Rio, instalada no município de Seropédica.

Os problemas causados pela destinação final inadequada dos resíduos são inúmeros. Quando não coletados, esses resíduos favorecem o entupimento de galerias de águas pluviais, aumentam a incidência de doenças, facilitam proliferação de insetos, roedores, aves e outros animais capazes de transmitir agentes infectantes ao homem, potencializam a poluição de corpos hídricos, promovem os incômodos oriundos do odor e, de modo geral, degradam o ambiente. Mesmo quando coletados, mas destinados aos lixões, há contaminação do solo e do lençol freático por chorume oriundo do processo de decomposição do lixo, poluição do ar pela emissão de gases poluentes, principalmente o gás metano, entre outros riscos ambientais. Os lixões também são atraentes aos trabalhadores que buscam materiais descartados de valor comercial, mas ficam submetidos ao trabalho insalubre no local.

O Aterro Metropolitano do Jardim Gramacho foi oficialmente fechado em junho de 2012, encerrando as atividades iniciadas a partir do convênio entre FUNDREM, COMLURB e prefeituras da região metropolitana.

A decisão pelo encerramento dos lixões no município contribuiu para a diminuição dos índices de poluição do ar, do solo e, no caso do lixão de Jardim Gramacho, da Baía de Guanabara. Proporcionou também o controle na disposição final dos resíduos coletados.

O município do Rio de Janeiro, pela primeira vez, realiza investimentos em infraestrutura necessários ao confinamento dos resíduos, adotando novas técnicas e tecnologias. Em consonância com a nova legislação em vigor, conta com procedimentos que proporcionam o tratamento dos gases e do chorume, como também a utilização de métodos de impermeabilização do solo.

Se, por um lado, houve maior controle na disposição final, ganhos ambientais, atendimento aos propósitos legais e institucionais, fomentando também a participação da iniciativa privada, por outro, a nova rede geográfica promoveu o fim do trabalho informal de aproximadamente 1.500 catadores que retiravam do lixo os materiais recicláveis de valor comercial. Além disso, desarticulou o comércio ligado aos antigos lixões, como também promoveu o aumento acentuado das subvenções do município do Rio de Janeiro para atendimento dos serviços de limpeza urbana, ultrapassando o valor de um bilhão de reais no ano de 2014.

O crescimento da geração de resíduos é constante e demanda investimento público para a manutenção dos serviços de coleta e destinação. A rede de coleta e destinação dos resíduos, embora atenda ao interesse público com a Companhia de Limpeza Urbana (COMLURB), tem a participação de empresas privadas por meio da concessão de serviços. Há uma participação fracionada de empresas privadas nessa rede; os fluxos de resíduos resultantes da coleta em residências e equipamentos públicos se vinculam aos fixos operados por empresas especializadas na captação e destinação às estações 
de transferência. Os fluxos entre as estações de transferência e a central de tratamento (fixos) são operados por apenas uma empresa, responsável pelo fluxo de maior volume.

Embora em funcionamento, vale ressaltar que a capacidade operacional da nova rede não está em sua plenitude. Há outras duas estações de transferência em fase de implantação, previstas para operarem nos bairros da Penha e Tanque. Ainda, a partir do funcionamento dessas estações, haverá a ampliação desta nova rede geográfica, tornando mais intenso os fluxos de resíduos em função da maior capacidade de drenagem nos fixos.

A geração constante e crescente de resíduos e a vida útil da Central de Tratamento de Resíduos (CTR Rio), estimada entre 15 a 25 anos, impõem o aperfeiçoamento de novos modelos para a gestão de resíduos e o aprofundamento das pesquisas ligadas ao tema - um desafio à população carioca, visto que já estamos no quinto ano da vida útil mínima, ou seja, um terço de sua capacidade mínima estipulada.

A nova rede geográfica, refletida na realização do projeto CTR Rio, não oferece solução permanente para o problema de destinação. Ao fim de sua vida útil, haverá necessidade de um novo destino para o lixo.

A demanda por destinação é permanente e urgente. A população quer o lixo fora de sua casa, de sua rua, de seu bairro, o mais distante possível. Vale ressaltar que o município do Rio de janeiro não absorve os resíduos gerados por sua população, que, em sua totalidade, são enviados ao município de Seropédica. Embora a discussão sobre o tema tenha grande importância, não faz parte do cotidiano da população. A maioria desconhece o destino do lixo que é gerado em suas residências ou nos espaços públicos.

Entendemos que todas as ações focadas no consumo se refletem na geração de resíduos. O impacto de sua promoção na sociedade determinará as variáveis pertinentes à configuração da rede de coleta e destinação. Ao dispor dessa rede no município, a população tem a possibilidade de utilizar o fluxo direcionado ao tratamento específico dos resíduos sólidos, diminuindo as mazelas oriundas do despejo irregular.

O consumo orienta a geração de resíduos sólidos urbanos que, por sua vez, demanda uma rede geográfica para a coleta e destinação final. A intensidade desse consumo determinará também a vida útil da nova rede.

Portanto, será necessária a observação das ações pertinentes ao consumo para percepção das nuances da nova rede geográfica de destinação dos resíduos urbanos e da espacialização do lixo no município do Rio de Janeiro.

\section{REFERÊNCIAS}

ABREU, M. A. Evolução Urbana do Rio de Janeiro. 4. ed. Rio de Janeiro: Instituto Pereira Passos, 2013.

AIZEN, M. \& Pechman, R. Memória da Limpeza Urbana no Rio de Janeiro. Rio de Janeiro: COMLURB, 1985.

BRASIL. Lei ${ }^{\circ}$ 12.305, de 2 de agosto de 2010. Institui a Política Nacional de Resíduos Sólidos; altera a Lei no 9.605 , de 12 de fevereiro de 1998; e dá outras providências. Diário Oficial [da] República Federativa do Brasil, Brasília, DF, 3 ago. 2010. Seção 1, p. 3.

BRASIL. Ministério do Meio Ambiente. Plano Nacional de Resíduos Sólidos. Brasília, DF, set. 2011. (Versão preliminar para consulta pública).

CORRÊA, R. L. Trajetórias geográficas. Rio de Janeiro: Bertrand Brasil, 2010.

EIGENHEER, E. M. Lixo: A limpeza urbana através dos tempos. Porto Alegre: Pallotti, 2009.

EMPRESAS ASSOCIADAS ABRELPE. Panorama dos Resíduos Sólidos no Brasil. São Paulo: [S.n.], 2013.

INSTITUTO DE PESQUISA ECONÔMICA APLICADA - IPEA. Diagnóstico dos Resíduos Sólidos Urbanos. Brasília: IPEA, 2012.

INSTITUTO PEREIRA PASSOS. Dados Saneamento Básico. Rio de Janeiro: IPP, 2014.

INSTITUTO BRASILEIRO DE GEOGRAFIA E ESTATÍsTICA. Atlas do Censo Demográfico. Rio de Janeiro: IBGE, 2010.

ORGANIZAÇÕES DAS NAÇÕES UNIDAS. Manifesto Ambiental. Estocolmo: ONU, 1972. 
RIO DE JANEIRO (RJ). Prefeitura. Relatório final - GT Aterro Sanitário. Rio de Janeiro, 2009. RIO DE JANEIRO (RJ). Prefeitura. Plano Municipal de Gestão Integrada de Resíduos Sólidos PMGIRS da Cidade do Rio de Janeiro: agosto de 2012 - agosto de 2016. Rio de Janeiro, RJ, 2012. RIBEIRO, M.A. Abordagens analíticas das redes geográficas. BOLETIM GOIANO DE GEORAFIA, janeiro/ dezembro - 2000 .

RODRIGUES, A.M. Produção e consumo do e no espaço: problemática ambiental urbana. São Paulo: Edição do autor, (S.d.).

UNIDAS, O.D. Relatório Pnuma. [S.1.]: [S.n.], 2010.

WADMAN, Maurício. Lixo: Cenários e Desafios: Abordagens Básicas para Entender os Resíduos Sólidos. São Paulo: Cortez, 2010. 